\title{
O ISSQN e as operações de Leasing
}

The ISSQN and leasing operations

Camilla Maithe de Ungaro Silva ${ }^{1}$

Aline Teixeira Tomazela ${ }^{2}$

\begin{abstract}
Resumo
O presente artigo analisa a questão da incidência do ISSQN sobre as operações de arrendamento mercantil, a qual está prevista na Lei Complementar no 116/2003, e trabalha o conceito de serviço em confronto à natureza do leasing. 0 trabalho também tem 0 propósito de expor a problemática acerca do conflito de competência entre Municípios nos referidos casos.
\end{abstract}

Palavras Chave: Competência; Serviço; Arrendamento M ercantil; Leasing

\section{Abstract}

This article examines the question of the impact of ISSQN on leasing operations, which is provided in Complementary Law No. 116/2003, and works the concept of service in comparison to the nature of the lease. The work also aims to expose the issue about the conflict of jurisdiction between municipalities in such instances.

Keywords: Competence, Service, Leasing, Leasing

\section{Introdução}

A problemática envolvendo o Imposto Sobre Serviços de Qualquer Natureza - ISSQN em operações de arrendamento mercantil, comumente chamadas de leasing, é antiga no Judiciário Brasileiro. Afinal, desde a edição do Decreto-Lei no 406/68, passando pela Lei Complementar no. 56/87, existe, ainda que implicitamente, a previsão da operação como sendo serviço. Em tempos mais recentes, a Lei Complementar 105/20013 também trouxe em sua lista anexa, dessa vez de forma expressa, a mesma previsão.

Ocorre que, em virtude da natureza jurídica do leasing e das características

\footnotetext{
${ }^{1}$ Acadêmica do 50 ano do Curso de Direito da Universidade Estadual de Londrina - UEL.

${ }^{2}$ Acadêmica do 50 ano do Curso de Direito da Universidade Estadual de Londrina - UEL.

${ }^{3} 15.09$ - Arrendamento mercantil (leasing) de quaisquer bens, inclusive cessão de direitos e obrigações, substituição de garantia, alteração, cancelamento e registro de contrato, e demais serviços relacionados ao arrendamento mercantil (leasing).
} 
inerentes à regra-matriz do ISSQN, especialmente quanto ao conceito de "serviço", surgem duas grandes questões que geram intermináveis discussões.

A primeira dela diz respeito à constitucionalidade das previsões legais de incidência do ISSQN sobre as operações de arrendamento mercantil. Isso porque, ainda que exista a previsão em Lei Complementar, a operação de leasing não se enquadra no conceito de serviço e, portanto, não seria constitucional a incidência sobre tal operação.

Já a outra discussão, que tem como premissa a validade da incidência, diz respeito à análise de qual Município seria competente para realizar a tributação respectiva. Isso porque, na maioria das vezes, os contratantes possuem domićlíios diferentes. A sede da instituição financeira, comumente é instalada nas grandes cidades, enquanto 0 arrendatário reside e realiza os pagamentos em local diverso.

0 presente artigo tem como proposta justamente expor as referidas problemáticas, apontando suas respostas mais lógicas e coerentes.

\section{A regra matriz do ISSQN}

O ISSQN (Imposto Sobre Serviços de Qualquer Natureza) veio a substituir o anterior IIP - Imposto Sobre Indústria e Profissões, com a Reforma Tributária implementada pela Emenda Constitucional $n-18 / 65$. Trata-se de tributo cuja competência para instituí-lo foi outorgada pelo Constituinte aos Municípios, conforme a previsão do art. 156, da Constituição Federal de 1988.

O ISSQN, assim como qualquer outro tributo, tem como antecedente da norma os critérios (i) material, (ii) espacial e (iii) temporal.

0 critério material, que será objeto de análise adiante, é aquele que indica um comportamento, tanto de pessoa física quanto jurídica que representa o núcleo da hipótese normativa que, no caso concreto, é o serviço. Assim sendo, de forma resumida, pode-se dizer que o critério material do ISSQN é a prestação por empresa ou profissional autônomo, com ou sem estabelecimento fixo, de serviços e desde que previstos na Lista Anexa à LC 116/2003.

Ressalta-se que não consubstancia serviço para fins de incidência tributária o serviço prestado a si próprio, o decorrente de vinculo empregatício, o de transporte interestadual e intermunicipal, o de comunicação, a prestação de serviços para o exterior, 
bem como a prestação de serviços pelo próprio poder público.

Já o critério espacial do ISSQN pode ser delimitado como sendo o território do Município em se que localiza a sede de quem presta o serviço ou então o local em que é efetivamente prestado o serviço, dependendo do tipo de serviço. Já o temporal é, em regra, 0 momento em que fora prestado o serviço. No entanto, dependendo da legislação municipal, podem ocorrer pagamentos em momentos diversos da efetiva ocorrência do serviço.

Em relação ao conseqüente da norma jurídica de incidência tributária têm-se os critérios (i) pessoal e (ii) quantitativo.

Primeiramente, em relação ao critério pessoal, tem-se como sujeito ativo o Município e como Sujeito Passivo, via de regra, o prestador de serviço. Já com relação ao critério quantitativo, a Lei Complementar 116/2003 pode ser utilizada para explaná-lo. 0 art. 70, da referida lei, traz como sendo a base de cálculo do ISSQN o preço do serviço. Já com relação à alíquota, dispõe seu art. 8 o que ela não excederá $5 \%$ (cinco por cento).

\section{Da materialidade do tributo. Previsão constitucional de incidência sobre serviço. Conceito de serviço}

A Constituição Federal de 1988, por meio de regras de competências, outorgou aos entes da federação, de maneira indelegável, poder para tributar determinados fatos presuntivos de riqueza. Nestes termos, a CF/88 ao outorgar competência para tributar, mediante impostos, elegeu certos fatos que indicam capacidade contributiva do indivíduo, precisando, assim, a própria materialidade do imposto.

Os entes aos quais foi outorgado o referido poder não podem tributar senão somente aqueles fatos, sob o risco de invasão de competência e lesão ao pacto federativo existente entre os entes da República. 0 referido pacto pressupõe autonomia legislativa dos entes federados e uniformidade de atuação entre eles. Com efeito, o fato tributável outorgado a um ente não pode, ainda que sob outra denominação, coincidir com outro fato de competência de outro ente.

Contudo, a CF/88 não trouxe um conceito expresso para esses fatos, sendo que inexiste na Carta Magna, por exemplo, o conceito explícito de renda. 0 que se sabe é que 0 constituinte outorgou ao legislador da União, por meio do art. 153, III, a faculdade de criar 
lei que institua um tributo que incida sobre a renda ou provento de qualquer natureza. Contudo, como não existe o conceito de renda, de qual forma se buscará o significado de renda para que se tribute efetivamente o que corresponde ao fato tributável? Em outras palavras, como ser irá tributar a renda, se o constituinte não diz o que é renda?

A resposta está na legislação infraconstitucional da época em que foi formada a Assembléia Constituinte e promulgada a Constituição. Nesse sentido, leciona HUMBERTO ÁVILA (2005, p. 122).

A CF/88, quando utiliza um termo, sem conceituá-lo de modo diverso, termina por incorporar o conceito que é utilizado no direito infraconstitucional vigente antes de sua promulgação.

Assim sendo, no momento em que for tributada a renda, não se pode classificar como renda outro fato que não se encaixe no conceito infraconstitucional consagrado de renda, sob pena de expressa violação à Constituição Federal e às regras de competência nela existentes.

Pois bem, especificamente no caso do Imposto Sobre Serviços de Qualquer Natureza, conforme anteriormente exposto, o Constituinte outorgou competência aos Municípios para instituírem e cobrarem o tributo sobre serviços de qualquer natureza, consoante expressa previsão do art. 156:

Art. 156 - Compete aos M unicípios instituir impostos sobre:

(...)

III - serviços de qualquer natureza, não compreendidos no Art. 155, II, definidos em lei complementar; (grifo nosso)

Assim, a atividade econômica (fazendo valer, assim, o Princípio da Capacidade Contributiva) de prestação de serviços é passível de tributação pelo Imposto Sobre Serviços de Qualquer Natureza - ISSQN.

Ocorre que, para a perfeita delimitação e exercício desta competência tributária atribuída aos Municípios, é imprescindível que se determine em que consiste a "atividade econômica de prestação de serviços", abstraindo conceito implícito na própria Constituição Federal, mediante a análise do conceito de serviço delimitado pelo legislador ordinário.

Ao ser editada Lei Complementar determinando quais serviços serão tributados 
pelo ISSQN, somente podem ser eleitos como serviços aqueles que de fato se subsumem ao conceito de "atividade econômica de prestação de serviços", sob pena de tributar materialidade não prevista na Carta Magna.

Da mesma forma, embora algumas atividades constem da lista de serviços veiculada pela Lei Complementar, somente a análise do caso concreto irá revelar se efetivamente existe a prestação de serviços; se houver, será possível a tributação pelo ISSQN, caso contrário, logicamente, não restará configurada a hipótese tributária. Nesse contexto, convém citar 0 art. $110^{4}$, do CTN, que expressamente prevê que a legislação tributária não pode alterar conceitos próprios do direito privado.

AIRES F. BARRETO (2003, p. 333) ao definir o conceito de serviço ensina:

Deveras, o serviço já de ser objeto de um contrato a que livremente aderiram prestador e tomador. A isonomia entre ambos, na relação contratual, é essencial à denotação do serviço tributável. o contrato engendra obrigação de fazer, em oposição à obrigação de dar. 0 prestador do serviço, ao assumir obrigação de fazer torna-se devedor, pelo contrato de prestação de serviço, de um determinado comportamento, consistente em praticar um ato ou uma série de atos (atividade), ou realizar uma tarefa da qual pode resultar uma vantagem para o tomador do serviço;

MARCELO CARON BAPTISTA (2005, p. 29), ao analisar a hipótese de incidência do ISS e, conseqüentemente, o conceito de serviço, tem idêntico posicionamento:

\begin{abstract}
A hipótese de incidência do ISS refere-se às prestações de fazer, ou seja, aquelas marcadas pela ação pessoal do devedor. Essa conclusão não se alcança com base na eficácia normativa experimentada por esse tributo ao longo do tempo mas por meio de indicativo colhido da própria Constituição Federal.

A palavra 'serviços', constante do art. 156, III, do Texto, afasta, por incongruência semântica, a idéia de prestação de dar, que não envolve, na sua essência, qualquer coisa, seja material, seja imaterial.
\end{abstract}

Em suma, tem-se que o serviço possui como essência a ação humana em prol de outrem. Quem contrata um serviço (tomador), busca do contratado (prestador) algum

\footnotetext{
${ }^{4}$ Art. 110. A lei tributária não pode alterar a definição, o conteúdo e 0 alcance de institutos, conceitos e formas de direito privado, utilizados, expressa ou implicitamente, pela Constituição Federal, pelas Constituições dos Estados, ou pelas Leis Orgânicas do Distrito Federal ou dos M unicípios, para definir ou limitar competências tributárias."
} 
benefício ou utilidade. 0 objeto do contrato é o trabalho humano, é a obrigação de fazer (e não de dar), personalizado, que gerará proveito ao tomador.

Diante de todo o exposto, conclui-se, então, que o legislador, ao enquadrar atividade que não consubstancia serviço na lista de anexa à Lei Complementar no 116/2003, certamente eivará de inconstitucionalidade a norma.

\section{Da não incidência de ISS sobre o Leasing}

Conforme se infere da breve explanação de conceitos consagrados de arrendamento mercantil e serviço, nota-se que há diferenças cabais entre os mesmos, razão pela qual instaurou-se uma celeuma no Judiciário a fim de discutir a validade das normas tributárias que instituem o ISS sobre o referido "serviço".

Com efeito, o leasing não pode ser considerado como serviço. Como exposto, o arrendamento mercantil não envolve prestações de fazer e nem é marcado pela ação pessoal de alguém. Trata-se, evidentemente, de contrato no qual prepondera a obrigação de dar.

Diante disso, nem mesmo o fato de a lei competente definida pela $\mathrm{CF} / 88^{5}$ para definir a lista de serviços que serão tributáveis, Lei Complementar 116/2003, é suficiente para ensejar a tributação sobre "serviço" de arrendamento mercantil.

Não obstante, em 1995, o Superior Tribunal de Justiça editou a Súmula №. 138, a qual tem o seguinte teor: "O ISS incide na operação de arrendamento mercantil de coisas móveis".

Acerca do posicionamento do STJ, convém algumas observações. Primeiramente destaca-se que o STJ não pode modificar o conceito de serviço. Isso porque seu conceito encontra-se inabalado junto ao direito privado. Resta então, ao legislador do direito tributário buscar esse conceito na legislação adequada para então enquadrá-lo para fins de incidência tributária. Se não caberia ao legislador tributário alterar tal conceito, muito menos seria de competência do Poder Judiciário modificá-lo, interpretando as leis além de seu possível sentido literal, sob pena de haver invasão ao Poder de competência do

\footnotetext{
5 "Art. 156 - Compete aos M unicípios instituir impostos sobre:

III - serviços de qualquer natureza, não compreendidos no Art. 155, II, definidos em lei complementar; “
} 
Legislativo.

Por outro lado, deve ser levado em consideração que o fato de haver expressa previsão constitucional de incidência sobre serviço afasta qualquer competência do STJ em proferir decisão definitiva acerca da matéria. Isso porque o art. 103 da CF/88 impõe que é de competência do Supremo Tribunal Federal julgar, mediante recurso extraordinário, as causas decididas em última instância, quando a decisão recorrida contrariar dispositivo da Carta Magna.

De fato, deve o STJ limitar-se a questões atinentes à legislação federal, deixando para o STF solucionar questões de cunho constitucional. Ciente disso, o próprio Tribunal, em recentes decisões ${ }^{6}$, vem reconhecendo o cunho constitucional da matéria, não conhecendo dos recursos especiais que a discutem.

O STF, pois, órgão do Poder Judiciário competente para proferir decisão definitiva acerca de discussões constitucionais, já se posicionou em casos que se aplicam perfeitamente aos de arrendamento mercantil.

No Recurso Extraordinário n 116.121-3/SP, cujo Relator foi o M inistro OCTÁVIO GAแOTTI, a máxima instituição do Judiciário debateu acerca da (in) constitucionalidade da incidência do ISS sobre a locação de bens móveis.

Neste citado processo, discutiu-se exatamente o mesmo objeto da questão central do presente trabalho: o conceito de serviço e a previsão de incidência de ISS sobre operações que não envolvam efetivamente a prestação de serviços.

Naquele caso, os defensores do contribuinte expuseram justamente que a locação não consubstanciaria serviço, em razão de sua natureza essencial de obrigação de dar, tal qual no caso do arrendamento mercantil. Nesse momento, convém trazer à baila trecho do voto proferido pelo Ministro MARCO AURÉLIO M ELLO:

\section{Em síntese, há de prevalecer a definicão de cada instituto, e somente a prestação de serviços, envolvido na via direta o esforço humano, é fato gerador do tributo em comento. Prevalece a ordem natural das coisas cuja força surge insuplantável; prevalecem as balizas constitucionais e legais, a conferirem segurança às relações Estado-contribuinte; prevalece, ao fim, a organicidade do próprio Direito, sem a qual tudo será possível no agasalho de interesses do Estado, embora não enquadráveis como primários.}

\footnotetext{
${ }^{6}$ Vide REsp 883953/SC, Rel. Ministro Castro Meira, Segunda Turma, DJ 09.03.2007 e REsp 805.317/RS, Rel.M inistro José Delgado, Rel. p/ Acórdão Ministro Luiz Fux, Primeira Turma, DJ de 21.09.2006
} 
Como se vê, o MM. Ministro foi cristalino ao afirmar que o serviço pressupõe uma obrigação de fazer, obrigação esta própria do ser humano, razão pela qual não se poderia, naquele caso, considerar a locação como sendo um serviço tributável, portanto, pelo ISSQN. Pelo mesmo motivo, não se pode considerar como válida a incidência do tributo municipal sobre 0 arrendamento mercantil.

Há quem argumente se tratarem de casos distintos, razão pela qual não se poderia aplicar o citado julgado nos casos de leasing. Ora, é flagrante a similitude entre a locação e o arrendamento mercantil. Conforme já exposto, HUMBERTO ÁVILA traz em seu conceito de arrendamento mercantil a palavra locação. E, muito embora os demais conceitos expostos possam não mencionar expressamente o termo locação, não se pode negar que a essência do instituto do leasing, assim como a locação, é a obrigação de dar. O que se tem, de fato, é que nenhum dos dois institutos pode ser taxado de serviço.

Com efeito, muito embora o STJ tenha editado a referida Súmula, o precedente do STF no RE 116.121-3 não poderia ser ignorado quando se julgam os casos envolvendo o ISS sobre o leasing. Trata-se, de fato, de uma decisão do órgão máximo do Poder Judiciário, competente para decidir sobre questões constitucionais, acerca de uma matéria de grande afinidade com o caso.

Então, diante do conceito de serviço e de arrendamento mercantil e da decisão proferida pelo STF, não resta outra conclusão senão a de que é inconstitucional a incidência do ISSQN sobre as operações de arrendamento mercantil.

\section{Do conflito de competência entre municípios nos casos de Leasing}

Ainda que se tenha concluído pela inconstitucionalidade da incidência de ISSQN sobre 0 arrendamento mercantil, a previsão encontra-se em plena vigência no ordenamento, em razão da previsão contida na lista anexa à Lei Complementar 116/2003. Diante disso, convém analisar a questão acerca do conflito de competência entre Municípios, mormente quando o STJ, ainda à época da vigência do Decreto Lei $n^{\circ}$ 406/68, firmou entendimento de que seria irrelevante o lugar do estabelecimento, devendo ser levado em consideração o lugar da "efetiva prestação" do serviço.

Isso porque os contratos de arrendamento mercantil podem ser firmados entre instituição localizada em determinada localidade do País e pessoas residentes nos mais 
diversos Municípios. Dessa maneira, pode eventualmente ocorrer a situação em que dois M unicípios cobrem o "serviço". Tanto o ente onde se localiza a sede da instituição, quanto 0 Município onde 0 arrendatário reside podem entender como sendo competentes para figurarem como sujeitos ativos da relação jurídico-tributária.

A fim de se definir qual seria o M unicípio competente para realizar a tributação, se faz imperioso entender e expor as etapas do arrendamento mercantil: (i) o procedimento inicia-se com a captação pela instituição financeira dos recursos necessários à compra do bem a ser arrendado; (ii) após tem-se o recebimento, análise e aprovação de proposta de celebração de contrato de arrendamento mercantil; (iii) em seguida passa-se à formalização e à celebração do contrato de arrendamento; (iv) então, ocorre a remessa, à entidade vendedora do bem dos recursos financeiros necessários à aquisição do bem; (v) e finalmente, os carnês para pagamento das parcelas do arrendamento são remetidos ao responsável pelo pagamento.

Pois bem, nota-se que, mesmo quando se trata de empresa com estabelecimentos nos mais diversos Municípios, as etapas principais da operação ocorrem em sua sede, razão pela qual não haveria motivo para outro Município tributar a operação senão aonde a mesma se localiza.

Ademais, conforme destacam HUGO DE BRITO MACHADO SEGUNDO e RAQUEL CAVALCANTI RAM OS MACHADO (2007, p. 139), a jurisprudência do ST) anteriormente citada foi formada a fim de evitar a fraude por parte das empresas prestadoras de serviço, que criam estabelecimentos "de fachada" em Municípios que oferecem alíquotas menores. Ocorre que, como é cediço, as grandes instituições financeiras possuem, via de regra, sede em grandes cidades, nas quais a alíquota do ISSQN é mais elevada.

Finalmente, a Lei Complementar 116/2003, em seu art. 3o prevê que o serviço considera-se prestado na sede da instituição:

Art. $3^{0} 0$ serviço considera-se prestado e o imposto devido no local do estabelecimento prestador ou, na falta do estabelecimento, no local do domićlio do prestador, exceto nas hipóteses previstas nos incisos I a XXII, quando o imposto será devido no local:

Com efeito, a legislação é expressa. Assim sendo, inconteste que o tributo é devido no local em que se situa a sede da empresa de leasing. 


\section{Conclusões}

Diante de todo o exposto, conclui-se que aceitar como válida a incidência do ISSQN nas operações de leasing significa alterar o conceito constitucional de serviço, ainda que este exista de forma implícita. Diante disso, haja vista a natureza de obrigação de dar que possui 0 arrendamento mercantil, não se pode concluir que há na referida operação a materialidade do tributo municipal que visa onerar aquele que exteriorize riqueza por meio da prestação de serviço. Diante disso, é inconstitucional a previsão contida no item 15.09, da lista anexa à LC 116/2003.

Com relação ao Município que seria competente para a cobrança do referido tributo, caso fosse válida a cobrança, não há maiores dificuldades em se concluir que será aquele no qual se localiza a sede da instituição.

\section{Referências}

ÁVILA, Humberto. Imposto sobre a Prestação de Serviços de Qualquer Natureza - ISS. Normas constitucionais aplicáveis. Precedentes do Supremo Tribunal Federal. Hipótese de Incidência, base de cálculo e local da prestação. Leasing financeiro: análise da incidência in Revista Dialética de Direito Tributário, 122, Novembro 2005.

BAPTISTA, M arcelo Caron. ISS: do texto à norma . São Paulo: Quartier Latin, 2005.

BARRETO, Aires F. ISS na Constituição e na Lei. São Paulo: Dialética, 2003.

CARVALHO, Paulo de Barros. Curso de direito tributário. 18ª ed. rev. e atual. São Paulo: Saraiva, 2007.

DÁCOM 0, Natália de Nardi. A hipótese de incidência tributária do Imposto sobre Serviços. São Paulo: Noeses, 2006.

DINIZ, M aria Helena. Curso de direito civil brasileiro. São Paulo: Saraiva, 1995, M ACHADO SEGUNDO, Hugo de Brito e M ACHADO, Raquel Cavalcanti Ramos. ISS e as operações de leasing in Revista Dialética de Direito Tributário, 139, Abril, 2007.

ROCHA, Valdir de Oliveira (coord.). O ISS e a LC 116.São Paulo: Dialética, 2003. SABBAG, Eduardo de Moraes. Direito Tributário. 9ạ ed. São Paulo: Premier Máxima, 2008 (Coleção Elementos do Direito) 